\title{
Sarcoidosis esplénica: una infrecuente causa de esplenectomía*
}

\author{
Drs. OSCAR TAPIA E. ${ }^{1}$, ENRIQUE BELLOLIO J. ${ }^{1}$, JUAN CARLOS ARAYA O. ${ }^{1}$
}

1 Departamento de Anatomía Patológica. Facultad de Medicina. Universidad de La Frontera. Temuco, Chile.

\section{Splenic sarcoidosis: a rare cause of splenectomy}

Mujer de 41 años con historia de 8 meses de dolor en hemiabdomen izquierdo, baja de peso y compromiso del estado general. Al examen físico se constataron adenopatías cervicales e inguinales y bazo acentuadamente aumentado de tamaño. El hemograma demostró anemia normocíticanormocrómica, sin alteraciones de la serie blanca ni megacariocítica. La tomografía computada de cuello, tórax y abdomen mostró ganglios linfáticos aumentados de tamaño a nivel submandibular, yugular, mediastínico, axilar, retroperitoneal e inguinal, y esplenomegalia de $21 \mathrm{~cm}$ (Figura 1). Se efectuó biopsia ganglionar que evidenció una linfoadenopatía granulomatosa no caseosa compatible con sarcoidosis. Se complementó estudio con niveles de enzima convertidora de angiotensina que resultaron elevados (271 U/L). Dado los hallazgos clínicos, de laboratorio e histopatológicos se diagnosticó una sarcoidosis y realizó esplenectomía.

El estudio macroscópico demostró un bazo de $19,8 \mathrm{~cm}$ de longitud mayor, de consistencia aumentada y levemente granular (Figura 2). El examen

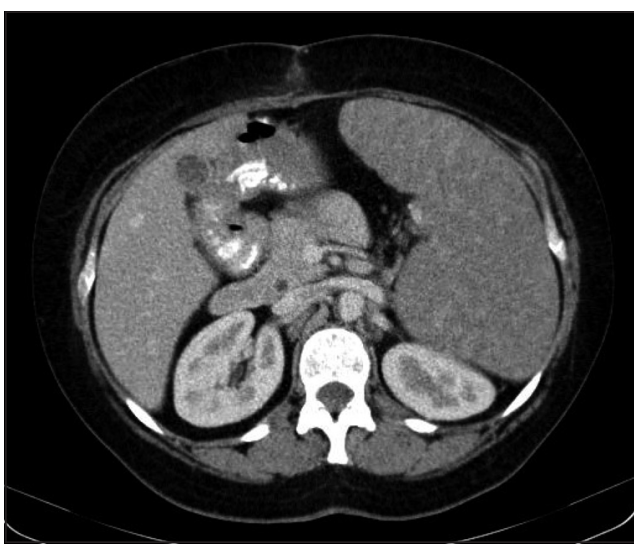

Figura 1. TC que muestra esplenomegalia.

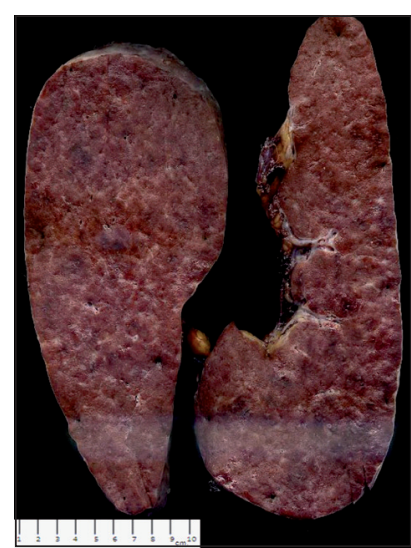

Figura 2. Pieza quirúrgica.

*Recibido el 10 de diciembre de 2012 y aceptado para publicación el 7 de enero de 2013.

Los autores no refieren conflictos de interés.

Correspondencia: Dr. Oscar Tapia E.

Manuel Montt 112. Código Postal 478-1176. Temuco, Chile.

otescalona@gmail.com 
microscópico reveló la presencia de abundantes granulomas epiteloídeos no caseificantes con presencia de cuerpos asteroides en el citoplasma de células gigantes multinucleadas. Los hallazgos histopatológicos fueron compatibles con una sarcoidosis esplénica. La paciente evolucionó sin complicaciones post-operatorias.

La sarcoidosis es una enfermedad granulomatosa multisistémica de etiología desconocida que habitualmente afecta a los pulmones y ganglios linfáticos intratorácicos, menos frecuentemente compromete los ojos, hígado, piel, hueso, miocardio, sistema nervioso, tubo digestivo y bazo. El compromiso esplénico en tanto se observa hasta en el $10 \%$ de los pacientes con sarcoidosis, siendo asintomático en $60 \%$ de estos pacientes y causando esplenomegalia importante en tan sólo el 3\%.

\section{Referencias}

1. Vardhanabhuti V, Venkatanarasimha N, Bhatnagar G, Maviki M, Iyengar S, Adams WM, et al. Extrapulmonary manifestations of sarcoidosis. Clin Radiol. 2012;67:263-76.

2. Mohan A, Sood R, Shariff N, Gulati MS, Gupta $\mathrm{SD}$, Dutta AK. Sarcoidosis manifesting as massive splenomegaly: a rare occurrence. Am J Med Sci. 2004;328:170-2. 